\title{
Circumstances Surrounding High-risk Sexual Experiences Among Primary Care Patients Living With and Without HIV
}

\author{
Rob J. Fredericksen, $P h D, M P H^{7}$, M. Walcott, $P h D^{2}$, F. M. Yang, PhD ${ }^{3}$, L. E. Gibbons, $P h D^{\prime}$, \\ E. Fitzsimmons, BA ${ }^{7}$, S. Brown, MPH, MSW' , K. H. Mayer, MD', T. C. Edwards, PhD ${ }^{7}$, S. Loo, MSc ${ }^{4}$, \\ C. Gutierrez, BA4 , E. Paez, MsC ${ }^{5}$, L. Dant, MPH' , W. C. Mathews, MD ${ }^{5}$, M. J. Mugavero, MD², \\ D. L. Patrick, $P h D^{7}$, P. K. Crane, $M D^{7}$, and H. M. Crane, $M D^{7}$
}

${ }^{1}$ Center for AIDS Research, University of Washington, Seattle, WA, USA; ${ }^{2}$ University of Alabama-Birmingham, Birmingham, AL, USA; ${ }^{3}$ Augusta University, Augusta, GA, USA; ${ }^{4}$ Fenway Community Health, Boston, MA, USA; ${ }^{5}$ University of California-San Diego, San Diego, CA, USA.

INTRODUCTION: Rates of sexually transmitted infection (STI) are rising in the USA, yet STI risk remains underaddressed by providers, even in HIV care, and with highrisk patients. We interviewed primary care patients living with and without HIV regarding circumstances surrounding sexual risk behavior to identify opportunities for providers to address and reduce STI risk.

METHODS: We conducted semi-structured 1:1 interviews with patients living with and without HIV reporting $\geq 1$ sex partner and varying STI exposure risk in the past 12 months from four geographically diverse US HIV and primary care clinics. We audio-recorded, transcribed, and coded interviews by circumstance type, using double-coding to ensure inter-coder reliability. We used Fisher's exact and $T$ tests to determine associations with demographic/risk factors.

RESULTS: Patients $(n=91)$ identified a mean of 3 of 11 circumstances. These included substance use (54\%), desire for physical/emotional intimacy (48\%), lack of HIV/ STI status disclosure (44\%), psychological drivers (i.e., coping, depression; 38\%), personal dislike of condoms (22\%), partner condom dislike/refusal (19\%), receiving payment for sex (13\%), and condom unavailability (9\%). Higher proportions of those who were high STI-exposure risk patients, defined as those with $\geq 2$ sex partners in the past 3 months reporting never or sometimes using condoms, reported disliking condoms $(p=.006)$; higher proportions of the high-risk and moderate-risk ( $\geq 2$ partners and condom use "most of the time") groups reported substance use as a circumstance $(p=.04)$.

CONCLUSION: Circumstances surrounding perceived STI exposure risk were diverse, often overlapping, and dependent on internal, environmental, and partner-related factors and inadequate communication. Meaningful care-based interventions regarding HIV/STI transmission behavior must address the diversity and interplay of these factors.

J Gen Intern Med 33(12):2163-70

DOI: $10.1007 / \mathrm{s} 11606-018-4675-4$

(c) Society of General Internal Medicine 2018

Received February 12, 2018

Revised July 12, 2018

Accepted September 4, 2018

Published online September 24, 2018

\section{INTRODUCTION}

Despite rising rates of sexually transmitted infection (STI) in the USA, ${ }^{1}$ providers, including HIV care providers, inconsistently discuss sexual risk behavior with their patients, ${ }^{2-10}$ even with patients known to be at high risk for contracting STI. ${ }^{4,8}$, 11, 12 Time constraints, provider discomfort discussing the topic with patients, and inaccurate perception of risk are key reasons. $^{3-5,13-18}$ Given this context, many providers are unaware of the circumstances surrounding their patients' sexual risk behavior. This lack of awareness may cause a missed opportunity to address root causes and factors contributing to it, some of which may be addressable in clinical care.

Discussions of sexual risk behavior in care have been shown to lead to additional screening and follow-up ${ }^{19}$ as well as positive clinical outcomes, ${ }^{20}$ and even brief risk-reduction counseling by providers has been found to reduce STI transmission. ${ }^{20-24}$ Clinic-based interventions targeting specific domains known to affect sexual risk behavior, such as substance use, ${ }^{25}$ have been effective in reducing condom-less sex. ${ }^{26,27}$ Given the effectiveness of such interventions, we sought to identify the nature of and interplay between circumstances surrounding high-risk sexual experiences among primary care patients living with and without HIV. We specifically sought to assess the extent to which such circumstances may be clinically addressable.

As part of an NIH-funded effort to develop an electronic patient-reported sexual risk measure for use in routine clinical care, we interviewed patients from multiple sites across the USA regarding their sexual behavior, specifically, the circumstances surrounding personal sexual experiences that they believe resulted in, or placed them at risk for acquiring or transmitting, STI including HIV.

\section{METHODS}

\section{Study Population and Recruitment}

We approached patients living with and without HIV for individual interviews at four US clinics within the Centers 
for AIDS Research Network of Integrated Clinical Systems (CNICS) between late 2014 and early 2015: Fenway Community Health- Boston, MA; 1917 Clinic at University of Alabama-Birmingham; Owen Clinic at University of California at San Diego; and Madison Clinic at Harborview Medical Center/University of Washington-Seattle. Patients living with $\mathrm{HIV}$ at these clinics respond to an electronic, computer tabletbased assessment of patient-reported measures and outcomes (PROs) before visits as part of clinical care. PROs included a sexual risk measure to determine study eligibility. Eligible patients indicated on the PROs having had anal or vaginal sex in the past year with 1 or more partners. We approached them on the same day as their clinic visit. We screened HIVuninfected patients by phone for eligibility. We recruited a convenience sample with heterogeneous numbers of partners and risk levels. We sought to enroll a group with over half of subjects with $\geq 2$ sex partners over the past year and sought to enroll a group with heterogeneous HIV/STI exposure risks, based on the model by Murphy et al. ${ }^{28}$ We defined those other than women who have sex with women (WSW) who reported using condoms "never" and "some of the time" as a high-risk group; those who reported using condoms "most of the time" as a moderate-risk group; and those using condoms "all of the time" as the lowest risk group.

We sought robust representation of groups at highest risk for HIV/STI: transgender women, cis-gender men who have sex with men (MSM) and/or men who have sex with both men and women (MSMW), and cis-gender women who have sex with men exclusively or who have sex with men and women (WSM/WSMW). We attempted to match interviewer and participant sex to minimize patient discomfort; transgender patients chose the sex of their interviewer.

\section{Patient Interviews}

A multidisciplinary team of HIV care providers and researchers designed an in-depth interview guide based on a literature review of measures of sexual risk behavior, attitudes/beliefs about HIV/ STI transmission, and barriers to safer sex. We interviewed participants for $\sim 60 \mathrm{~min}$, offering \$25 compensation. We asked patients what they understood about HIV/STI transmission and prevention, then explored attitudes about "risky" vs. "safe" sex, before asking about their own past and current sexual behaviors. The specific prompt for this work was "Are there times when it's harder than usual to avoid what you would consider 'risky sexual behavior?' If so, when are these times?"

\section{Interview Coding}

An independent transcription agency transcribed interview audio recordings. We coded transcripts using Dedoose webbased qualitative analysis software. ${ }^{29}$ Coding analysts were comprised of CNICS-based Masters and Doctorate-level social science and public health researchers representative of a broad range of disciplines including anthropology, epidemiology, behavioral science, and psychology. In order to guard against the possible influence of pre-conceived ideas influencing interpretation of data, we tasked three coders of intentionally varied disciplines to independently develop codes for types of circumstances based on a subset of 15 of the same transcripts, using an open-coding process. We achieved consensus regarding the final set of codes through facilitated discussion of the candidate coding schematics during an analyst conference call.

Upon establishing the final codes, two analysts independently performed coding for all transcripts; we addressed and reconciled differences in interpretation during a weekly analyst call. We evaluated for thematic saturation, the point at which no new themes emerge from additional interviews, at approximately every ten interviews; this number of completed interviews typically coincided with weekly analyst calls, which included study interviewers. The qualitative project leader summarized all emergent themes found within the coded categories of interview transcripts, and study interviewers confirmed whether new themes (circumstances surrounding sexual risk behavior) had emerged from the yet-to-be transcribed interviews.

\section{Statistical Analysis}

We used Fisher's exact and $T$ tests to determine associations with demographics and risk factors.

\section{RESULTS}

\section{Quantitative Results}

We interviewed $n=91$ patients [ 68 and 23 patients living with and without HIV, respectively (75\% and 25\%, see Table 1)]. High STI-exposure risk patients, defined as those with $\geq 2$ sex partners in the past 3 months reporting never or sometimes using condoms, were most likely to say they disliked condoms ( $p=.006)$; these and moderate-risk patients $(\geq 2$ partners and condom use "most of the time") were most likely to identify substance use as a circumstance $(p=.04)$. A higher proportion of patients living with HIV identified partner refusal of condoms as a circumstance, though this was not significant $(p=.06)$.

\section{Results of Concept Elicitation and Item Matching}

We reached thematic saturation at $n=90$. Many patients reported more than one co-occurring circumstance surrounding condom-less sex, and reported a mean of 3 of 11 identified factors listed below. Table 2 shows the percentage of patients citing each factor. These included substance use (reported by $54 \%$ of patients), desire for physical or emotional intimacy (48\%), lack of HIV/STI status disclosure (44\%), psychological drivers (i.e., coping, depression) (38\%), personal dislike of condoms (22\%), partner condom dislike/refusal (19\%), receiving 
Table 1 Demographics

\begin{tabular}{|c|c|}
\hline Total & 91 \\
\hline \multicolumn{2}{|l|}{ HIV serostatus } \\
\hline $\mathrm{HIV}+$ & $68(75 \%)$ \\
\hline HIV- & $23(25 \%)$ \\
\hline \multicolumn{2}{|l|}{ Present sex } \\
\hline Male & $53(58 \%)$ \\
\hline Female & $28(31 \%)$ \\
\hline MTF transgender & $6(7 \%)$ \\
\hline FTM transgender & $4(4 \%)$ \\
\hline \multicolumn{2}{|l|}{ Race } \\
\hline African-American & $31(34 \%)$ \\
\hline White & $50(55 \%)$ \\
\hline Asian-American, Hawaiian, Pacific Islander & $3(3 \%)$ \\
\hline Native American & $0(0 \%)$ \\
\hline More than one race or other race & $7(8 \%)$ \\
\hline Latino/Hispanic, any race & $8(9 \%)$ \\
\hline \multicolumn{2}{|l|}{ Age } \\
\hline$<30$ & $24(26 \%)$ \\
\hline $30-39$ & $20(22 \%)$ \\
\hline $40-49$ & $24(26 \%)$ \\
\hline$\geq 50$ & $23(25 \%)$ \\
\hline \multicolumn{2}{|l|}{ Sexual orientation, by behavior* } \\
\hline MSM** & $44(48 \%)$ \\
\hline MSMW & $10(11 \%)$ \\
\hline MSW** & $22(24 \%)$ \\
\hline WSM*** & $35(38 \%)$ \\
\hline WSMW & $9(10 \%)$ \\
\hline \multicolumn{2}{|l|}{ Sexual risk level**** } \\
\hline High & $26(29 \%)$ \\
\hline Moderate & $34(37 \%)$ \\
\hline Low & $31(34 \%)$ \\
\hline \multicolumn{2}{|l|}{ HIV+ ONLY } \\
\hline \multicolumn{2}{|l|}{ Time since initial HIV diagnosis } \\
\hline $0-5$ years & $26(38 \%)$ \\
\hline $6-10$ years & $15(22 \%)$ \\
\hline$>10$ years & $27(39 \%)$ \\
\hline \multicolumn{2}{|l|}{ Route of transmission } \\
\hline MSM & $34(50 \%)$ \\
\hline MSM/IV drug use & $3(4 \%)$ \\
\hline IV drug use (non-MSM) & $4(6 \%)$ \\
\hline Heterosexual & $19(28 \%)$ \\
\hline & $8(12 \%)$ \\
\hline \multicolumn{2}{|l|}{ Most recent CD4 count (cells $/ \mathrm{mm}^{3}$ ) } \\
\hline $0-199$ & $3(4 \%)$ \\
\hline $200-349$ & $5(7 \%)$ \\
\hline$\geq 350$ & $60(88 \%)$ \\
\hline
\end{tabular}

*Transgender patients represented by sex corresponding to current gender identity

**Includes men who have sex with men and women

***Includes women who have sex with women and men

$* * * *$ High risk, $2+$ sex partners in past 6 months and condom use "never" or "some of the time"

Moderate risk, $2+$ sex partners in past 6 months and condom use "most of the time"

Low risk, condom use "all of the time" with one or more partners

MTF, male to female (transgender)

FTM, female to male (transgender)

MSM, men who have sex with men

$M S M W$, men who have sex with men and women

MSW, men who have sex with women

WSM, women who have sex with men

WSMW, women who have sex with men and women

WSW, women who have sex with women

payment for sex (13\%), and condom unavailability $(9 \%)$.

In the following interview excerpts, patients describe circumstances they believe to have increased their STI risk. Patient sexual orientation and age are listed after each.
Table 2 Circumstances Surrounding Condom-Less Sex

\begin{tabular}{ll}
\hline \hline Substance use & $54 \%$ \\
Desire for physical/emotional intimacy & $48 \%$ \\
Lack of HIV/STI disclosure & $44 \%$ \\
Psychological drivers & $38 \%$ \\
Personal dislike of condoms & $22 \%$ \\
Partner dislike/refusal of condoms & $19 \%$ \\
Receiving payment for sex & $13 \%$ \\
Condom unavailable & $9 \%$ \\
Desire for pregnancy & $3 \%$ \\
Condom failure & $1 \%$ \\
Forced sex & $1 \%$ \\
\hline
\end{tabular}

\section{Substance Use}

Substance use was the most common circumstance reported, with methamphetamine and alcohol use the most commonly mentioned substances believed to interfere with judgment surrounding sexual risk behavior. Whereas alcohol use generally led to incapacitation or resignation to partner pressure for condom-less sex, notably, methamphetamine use among MSM fueled a highly proactive pursuit of risky sex:

[Crystal meth]... lowered my inhibitions and changed my role. Before that...I was topping mostly with a condom. And then it was just whatever...not just topping anymore or using condoms anymore. MSM, 26

When I do a shot of meth I turn into a power bottom... I've been at [a bathhouse] several times and I had a guy walk into my room... he had a condom in his hand... I said either the condom goes or you go. I didn't come here for safe [sex]. When I'm on [crystal meth] I want it as dirty and as nasty as I can get it. MSMW, 33

One man living with HIV echoed others in his description of the use of methamphetamine to overcome inhibitions of having sex with other men, using it to "throw himself" into a sexual situation with less anxiety.

\section{Lack of HIV/STI Disclosure}

Patients reported problems surrounding HIV/STI disclosure. Some patients living with HIV reported becoming infected in the context of partners falsely claiming to be HIV-negative. A common barrier to disclosure among these patients was the experience of anticipated or actual HIV-related stigma, a phenomenon that combined fears of rejection and loss of confidentiality:

[A potential sex partner] says, oh, by the way I'm negative. How about you? And you have to say you're 
positive... that whole hookup is gone and you don't know if they're gonna go and talk to everyone else. MSM, 50

Well, you'll be in that moment and as soon as you bring [your HIV positive status] up, it just kills the whole... it's like there's been a trust broken, or you just stole their wallet. MSMW, 44

Several patients simply did not discuss HIV/STI status at all, creating a circumstance of uncertain risk. Often this was because patients presumed their partners to have the same status as themselves, or, if partners were HIVnegative, "knew the risks". Assumptions of HIV status were at times based on the nature of a particular website on which they met, and/or venue of the sex. As one patient living with HIV describes:

So there is this online [condom-less sex-themed] site that I went to....I was just of the impression that... when I kept reading profiles, I said 'okay, all of these persons are positive or undetectable.'...truly, no inhibitions exist on this site. So I hooked up with this particular dude [from the website]...in the middle of having sex, he says, 'You're negative, right?' I'm like, 'Yeah.' And I'm like 'did I just tell this dude I'm negative?' ...we're not using a condom and I'm about to come inside you, and you're gonna tell me you're negative? Seriously? MSMW, 26

Lack of disclosure was even more marked in group sex environments:

[A group sex party] is sexually charged when you go in and that's what everybody is there for....you don't have to play this little game... to, like, get somebody to, you know, fuck around with you... with groups... the switch just, like, turns off. Like, 'okay, [I'm] getting down to it. I really don't care right now.' MSM, 49

In a group [sex] situation, I'm not going to discuss my [HIV positive] status, and I would be surprised if they discussed their status. Occasionally that happens, but that's really uncommon. MSM, 46

\section{Psychological Attributes}

Several patients described the influence of personal psychological attributes on their own sexual risk behavior.
Sex as a general coping mechanism to feel better was common:

I was probably emotionally distraught... I didn't have a job and I think I was unemployed for four months ... all my bills were building up, my rent was building up, and so my living situation was getting rocky and I think that caused the lower inhibitions and promiscuity that I had. MSM, 26

I didn't do something correctly at work, I lost my job or I felt less than... anytime I felt like I needed some kind of positive input, sex became a means of making me feel better about who I am, because I was able to attract somebody. MSM, 48

Others reported depression as a reason for not using condoms:

....what's the point? I'm down, I'm sad....who cares if I don't use a condom? Who cares if the person infects me? I guess when our feelings are shot we don't care so much about our physical health or whatever else. MSMW, 33

When I have really bad depression, I find myself being more risky sexually....I think it's I just don't care about my future and that kind of thing. WSMW, 23

\section{Desire for Sexual and/or Emotional Intimacy}

Several patients reported desire for sexual and/or emotional intimacy as a circumstance surrounding risk acceptance, in the form of condom-less sex. Many of these patients reported the urge to have sex as overwhelming the need to protect oneself, and described needing or wanting to "be in the moment," or of being swept away by a "moment."

Sometimes if the person is just really good looking and just has a really nice body sometimes, and then you'll say, okay, what the hell, I'll just do it... this nice looking person wants to be with me....you just let your guard down. MSM, 52

Patients also linked condom-less sex to the fulfillment of emotional intimacy:

Even though I'm with the partner who infected me and we started off using condoms ... neither of us were 
feeling the excitement that we want, the emotions that we want for each other, so we'll take [the condom] off. WSM, 38

I think the most challenging when it comes to thinking about [condom] protection is just feeling like you can't be as close to that person, so it is also like a barrier and sometimes you don't want that barrier. WSMW, 23

\section{Condom Dislike}

Some patients reported disliking condoms, with most reporting reduced quality of sex when using them:

You might as well jack off instead...you want the enjoyment of sex. MSM, 49

The sex is totally different, you don't get the real feeling with using a condom...just uncomfortable, not enjoyable at all. WSM, 38

Others described difficulty for themselves or a male partner to maintain erections or achieve orgasm when using condoms:

He wore a condom, but he wasn't able to keep it up....he got so frustrated with condoms that he's like, "This isn't gonna work." WSM, 47

I was with a partner who was like, 'I can never finish with a condom'. MSM, 31

\section{Partner Reluctance or Refusal to Use Condoms}

Some patients reported partner reluctance or refusal to use condoms, in circumstances in which it was the patient's stated preference to use them. Non-use sometimes occurred with the patient's consent, sometimes not:

If I'm with somebody who clearly isn't enjoying the condom situation then I'm more likely to be like okay you can remove it. WSM, 24

The most challenging thing is ensuring your [partner's] condom is in place, because I've messed around with a couple of people and as soon as I'm not looking they'll take the condom off. MSMW, 44
Some patients described a degree of persuasiveness or manipulation from the partner to not use condoms:

I feel guilt tripped...every time I want to use a condom and they don't. MSM, 32

...it's a 'If you trust me, and if it's just you and I, why should I? You're okay, I'm okay.' [I asked] 'Have you been to the doctor?' 'No.' ....'When was the last time you've been to the doctor?' [He said] 'Girl, you know I can't afford the doctor. I ain't got no money. I ain't been to no clinic. I don't have no disease.' WSM, 51

Sometimes fear of abandonment drove patients' lack of condom use. In the words of one patient:

[Sex partners] ... kind of look down on you for using a condom, and it just causes problems if you try to develop a relationship with someone... they don't want to have anything to do with you, and you might like that person. So it puts you in a compromising position, so you say, okay...I'll go ahead and do it. MSM, 52

One patient living with HIV described that her HIVnegative husband felt entitled to condom-less sex with her:

Cause, like he said, "That's my wife. I'm not gonna use a condom. I'm with my wife. I married her for better or worse. Whatever she got I, if I get it, I get it." That's his attitude. WSM, 43

\section{Condom Availability}

Some patients cited lack of available condoms. A few patients indicated a latex allergy, and cited expense and lack of availability of non-latex condoms. Most patients, however, reported not carrying condoms because they did not expect to have sex.

If I'm at the gym or something like that, it's happened that I've had unsafe sex. MSM, 32

...my condoms are in my bedroom drawer, so unless I'm having sex in my bedroom, I don't have a condom with me. FTM Transgender, 52, no sexual orientation given 
Some women held the expectation that the male partner would provide the condom.

The most challenging thing? Being prepared I guess...I think that a lot of females... don't bring protection. They kind of expect the other person to have it. WSM, 24

Perhaps relatedly, another woman noted the potential stigma of carrying condoms:

So using a condom, for a black woman... she cannot afford to get caught with condoms in her purse or on her person. If the male doesn't bring them, it's not gonna happen. WSM, 51

\section{Combined Factors}

Patients described a mean of 3 co-occurring circumstances surrounding sexual risk behavior, and this was reflected in some of their self-assessments:

Sometimes, I mean even I don't know why I would put myself at risk. .... it would be probably a little bit of everything from the environment to the drug use and alcohol, and just [a sex partner] being available. It kinda is a little embarrassing to say now, but I mean it's the truth. If a girl is willing, how do you say no? MSW, 39

If you act like you crazy [laughter]....you have too many dudes - and you a female - that's 'friends' [laughter], you know what I'm saying? All these are factors. Or if money changes your attitude [laughter] or alcohol make your clothes come off, it's - all these are factors that decide if you gonna wear a condom or not. MSW, 45

\section{Calculated Risk}

Several patients spoke of their decision to have condom-less sex as a conscious risk assessment:

If I know someone and we've had conversations about their HIV status, and they're negative, and I have some idea that they are... having safe sex otherwise, or not having a lot of sex, I'm more likely to have bareback sex with them. MSM, 32

One virally suppressed patient living with HIV echoed others in his decision to not wear condoms with his partner:
I don't use condoms unless I discover that hey, my viral load is way out of whack, so I've got a higher risk of infecting my wife. So yeah, [at that point] of course I'm going to do whatever I can to protect her. MSW, 35

The non-use of condoms between long-term partners was often a mutual decision taking many factors into account, such as perceived partner sexual fidelity and, for patients and/or partners living with HIV, whether or not viral load was detectable.

\section{DISCUSSION}

Patients described a variety of factors and circumstances that contribute to sexual risk behavior. Circumstances spanned dimensions of personal agency, power dynamics, psychological attributes, and environment. Concurrence of factors was common. Providers should be aware that in many cases, sexual risk behavior may be multifactorial, with interrelated and mutually reinforcing factors that may prove recalcitrant to simplistic interventions. For example, a common theme was that the desire to feel good, or to at least feel better, was so strong that it outweighed self-preservation. This manifested in a variety of ways, such as, among patients living with HIV, a desire for intimacy overwhelming anticipated rejection due to HIV status disclosure or the use of intoxicants to alleviate depression or social anxiety prior to sex. Such circumstances resulted in non-disclosure and subsequent condom-less sex. Any or all of these factors, and many others, could be present in a single condom-less sex event.

Despite this complexity, many options are available to address factors contributing to sexual risk behavior at the point-ofcare level, beyond the standard promotion of condom use, and the prescription of antiretroviral medications and/or preexposure prophylaxis (PrEP) to patients and partners who engage in condom-less sex. Screening and discussion of substance use, the most commonly cited circumstance among our patients, is one such option. Substance use counseling and/or treatment have been shown to reduce STI risk behavior. ${ }^{27,} 30$ Psychological drivers for condom-less sex are also often clinically addressable. Depressive symptoms, for example, were commonly endorsed by the patients we interviewed, and many expressed the use of sex to cope with difficult life circumstances, to "feel better," or to provide escape, echoing similar findings elsewhere. ${ }^{31-33}$ Recent multi-site US studies have found associations between depression and sexual risk behavior. ${ }^{34,}{ }^{35}$ Identifying and treating depression may be an important intervention for reducing sexual risk behavior. Furthermore, providers may wish to specifically address with patients the roles that substance use and depression play in sexual risk behavior.

Non-disclosure of HIV infection prior to sex was common among the patients we interviewed. Some patients living with 
HIV expressed past intent to disclose without following through; others expressed regret for non-disclosure. These findings suggest that practical assistance, such as communication skill-building specific to HIV/STI disclosure, may be welcomed by some patients. Motivators against disclosing included fear of consequences such as stigmatization, rejection, and loss of confidentiality. Given these potential consequences, it may be beneficial to pair interventions promoting HIV disclosure with skill development that will enable patients living with HIV to assess and cope with HIV-related stigma. Among MSM, interpersonal skills trainings have proven effective in reducing sexual risk behavior. ${ }^{36}$ Among patients living with HIV, disclosurerelated interventions increase confidence to disclose and have improved both communication skills and mental health outcomes. Coupled with safer sex interventions, patients have found these interventions to be acceptable and useful. ${ }^{37}$ "Safer sex" interventions with a disclosure training component reduced the number of partners and sex acts, ${ }^{37}$ as well as incidents of unprotected receptive anal sex. ${ }^{38}$

Several patients expressed the desire for physical and/or emotional intimacy as a key reason for condom-less sex, as has been found in other studies. ${ }^{39-41}$ Many patients mentioned being caught up in "the moment," with mixed intent to use condoms. Such moments were at times regarded as a loss of control over judgment, yet they were also valued as a "pure" expression of intimacy. The desire for "pure" expressions of intimacy often overwhelmed the acknowledged risk of STI transmission; "feeling good" and condom use were at times perceived as mutually exclusive. Harm reduction/disclosure counseling interventions may allow patients to more safely realize intimacy needs, as may offering PrEP to HIVuninfected patients and partners to reduce HIV transmission risk.

Condom-related problems were common among patients. Some described their own or partners' difficulty maintaining erections or achieving orgasm when wearing condoms. Erectile dysfunction treatment in these patients may help facilitate condom use. Furthermore, discussions of lubricants may be useful to improve acceptance of consistent condom use. Lack of condom availability, while a less prevalent concern, may be addressed through providing condoms at the point of care. Motivational interviewing to anticipate and negotiate sexual experiences has also proven effective. ${ }^{26,}{ }^{42-44}$ Some women reported difficulty with keeping condoms available due to perceived social stigma against women having them in their possession. For women with this concern, and for other patients to whom access to condoms may be stigmatized, motivational interviewing focused on this particular circumstance may prove to be useful.

For many high-risk patients who report high levels of sexual risk behavior, it occurs in the context of multiple reinforcing factors. Providers can help patients reduce the risk of sexual HIV/STI transmission by discussing contexts in which patients are most at risk and by identifying and addressing contexts that may be amenable to interventions.

\section{STRENGTHS AND LIMITATIONS}

We recruited a highly diverse sample of patients in terms of geography, race, HIV serostatus, gender, and sexual orientation. Due to low numbers of WSW who did not also have sex with men, our findings may be less relevant to lesbianidentified women/WSW who do not also have sex with men. We did not query perceived differential risk between specific STIs. Patients may have perceived some circumstances as riskier than others based on their perceived risk of exposure to specific STIs. Interviews concluded early in the PrEP era. No patients discussed being on PrEP or having partners on PrEP, so we did not gain knowledge about its use as a potential reason for condom-less or otherwise "risky" sex. More sensitive circumstances, such as forced sex or substance use, may have been under-reported by patients and may not be fully represented here.

\section{CONCLUSION}

Circumstances surrounding perceived STI exposure risk were diverse, often overlapping, and dependent on internal, environmental, and partner-related factors as well as lack of communication. Meaningful care-based interventions regarding HIV/STI transmission behavior must address the diversity and interplay of these factors, in particular, the role of drug and alcohol use, psychological drivers, and lack of disclosure.

Acknowledgments: We thank our patients for their time, candor, and insights.

Corresponding Author: Rob J. Fredericksen, $\mathrm{PhD}, \mathrm{MPH}$; Center for AIDS Research University of Washington, Box 359931, 325 9th Avenue, Seattle, WA 98104, USA (e-mail: rfrederi@uw.edu).

Funding This research was funded by a cooperative agreement awarded to the University of Washington (Principal Investigators: $D$ Patrick, $H$ Crane, P Crane) from the National Institute of Allergy and Infectious Diseases (NIAID) and National Institute of Arthritis and Musculoskeletal and Skin Diseases (NIAMS) (Grant No. UO1 AR057954). Support was also provided by the National Institute of Allergy and Infectious Diseases (NIAID) University of Washington Center for AIDS Research (Grant No. P30 AI027757), CNICS (R24 AI067039), National Institute of Alcohol Abuse and Alcoholism (NIAAA) (ARCH Grants U01 AA020802, UO1 AA020793, and U24AA020801), UAB Center for AIDS Research (CFAR) (Grant No. P30 AI027767), and the Patient Centered Outcomes Research Institute (PCORI) (Grant No. SC14-1403-14081).

\section{Compliance with Ethical Standards:}

Conflict of Interest: Dr. H. Crane reports a grant from ViiV Healthcare outside the submitted work. Dr. Mugavero reports personal fees from the Gilead Foundation and a grant from Bristol-Myers Squibb, and Dr. Mayer reports grants from Gilead Sciences and ViiV Healthcare outside the submitted work. All remaining authors declare that they do not have a conflict of interest. 


\section{REFERENCES}

1. Centers for Disease Control fact sheet: reported STD's in the United States. 2016.

2. Wimberly YH, Hogben M, Moore-Ruffin J, Moore SE, Fry-Johnson Y. Sexual history-taking among primary care physicians. J Natl Med Assoc. 2006,98: 1924-1929.

3. Talking with patients about sexuality and sexual health. In: Clinical fact sheets. Washington, DC: Association of Reproductive Health Professionals; 2010.

4. Glaude-Hosch JA, Smith ML, Heckman TG, Miles TP, Olubajo BA, Ory MG. Sexual Behaviors, Healthcare Interactions, and HIV-Related Perceptions Among Adults Age 60 Years and Older: An Investigation by Race/Ethnicity. Curr HIV Res. 2015, 13:359-368.

5. Savasta AM. HIV: associated transmission risks in older adults-an integrative review of the literature. $J$ Assoc Nurses AIDS Care. 2004,15:50-59.

6. Fredericksen R, Crane PK, Feldman BJ, Tufano J, Harrington RD, Dhanireddy S, et al. Impact of same-day pre-visit electronic patientreported outcome (PRO) collection on provider assessment of sexual risk and other behaviors of HIV-infected patients in routine clinical care. In: American Public Health Association 139th Annual Meeting. Washington, D.C.; 2011.

7. Gardner LI, Metsch L, Strathdee SA, del Rio C, Mahoney P, Holmberg SD, et al. Frequency of discussing HIV prevention and care topics with patients with HIV: influence of physician gender, race/ethnicity, and practice characteristics. Gend Med. 2008,5:259-269.

8. Marquez C, Mitchell SJ, Hare CB, John M, Klausner JD. Methamphetamine use, sexual activity, patient-provider communication, and medication adherence among HIV-infected patients in care, San Francisco 2004-2006. AIDS Care. 2009,21:575-582.

9. Laws MB, Bradshaw YS, Safren SA, Beach MC, Lee Y, Rogers W, et al. Discussion of sexual risk behavior in HIV care is infrequent and appears ineffectual: a mixed methods study. AIDS Behav. 2011,15:812-822.

10. Drainoni ML, Dekker D, Lee-Hood E, Boehmer U, Relf M. HIV medical care provider practices for reducing high-risk sexual behavior: results of a qualitative study. AIDS Patient Care STDS. 2009,23:347-356.

11. Wolitski RJ, Fenton KA. Sexual health, HIV, and sexually transmitted infections among gay, bisexual, and other men who have sex with men in the United States. AIDS Behav. 2011,15 Suppl 1:S9-17.

12. van Liere GA, Hoebe CJ, Niekamp AM, Koedijk FD, Dukers-Muijrers NH. Standard symptom- and sexual history-based testing misses anorectal Chlamydia trachomatis and neisseria gonorrhoeae infections in swingers and men who have sex with men. Sex Transm Dis. 2013,40:285-289.

13. Morin SF, Koester KA, Steward WT, Maiorana A, McLaughlin M, Myers JJ, et al. Missed opportunities: prevention with HIV-infected patients in clinical care settings. J Acquir Immune Defic Syndr. 2004,36:960-966.

14. Burd ID, Nevadunsky N, Bachmann G. Impact of physician gender on sexual history taking in a multispecialty practice. J Sex Med. 2006,3: 194-200.

15. Politi MC, Clark MA, Armstrong G, McGarry KA, Sciamanna CN. Patient-provider communication about sexual health among unmarried middle-aged and older women. J Gen Intern Med. 2009,24:511-516.

16. Hayes V, Blondeau W, Bing-You RG. Assessment of Medical Student and Resident/Fellow Knowledge, Comfort, and Training With Sexual History Taking in LGBTQ Patients. Fam Med. 2015,47:383-387.

17. Lurie N, Margolis K, McGovern PG, Mink P. Physician self-report of comfort and skill in providing preventive care to patients of the opposite sex. Arch Fam Med. 1998,7:134-137.

18. Tao G, Irwin KL, Kassler WJ. Missed opportunities to assess sexually transmitted diseases in U.S. adults during routine medical checkups. Am J Prev Med. 2000,18:109-114.

19. Meanley S, Gale A, Harmell C, Jadwin-Cakmak L, Pingel E, Bauermeister JA. The role of provider interactions on comprehensive sexual healthcare among young men who have sex with men. AIDS Educ Prev. 2015,27:15-26.

20. Fisher JD, Fisher WA, Cornman DH, Amico RK, Bryan A, Friedland GH. Clinician-delivered intervention during routine clinical care reduces unprotected sexual behavior among HIV-infected patients. J Acquir Immune Defic Syndr. 2006,41:44-52.

21. Patel P, Bush T, Mayer K, Milam J, Richardson J, Hammer J, et al. Routine brief risk-reduction counseling with biannual STD testing reduces STD incidence among HIV-infected men who have sex with men in care. Sex Transm Dis. 2012,39:470-474.
22. Rose CD, Courtenay-Quirk C, Knight K, Shade SB, Vittinghoff E, Gomez C, et al. HIV intervention for providers study: a randomized controlled trial of a clinician-delivered HIV risk-reduction intervention for HIV-positive people. J Acquir Immune Defic Syndr. 2010,55:572-581.

23. Gardner LI, Marks G, O'Daniels CM, Wilson TE, Golin C, Wright J, et al. Implementation and evaluation of a clinic-based behavioral intervention: positive steps for patients with HIV. AIDS Patient Care STDS. 2008,22:627-635.

24. Kamb ML, Fishbein M, Douglas JM, Jr., Rhodes F, Rogers J, Bolan G, et al. Efficacy of risk-reduction counseling to prevent human immunodeficiency virus and sexually transmitted diseases: a randomized controlled trial. Project RESPECT Study Group. JAMA. 1998,280:11611167.

25. HIV and substance use in the United States. Centers for Disease Control; 2018. Accessed September 19, 2018. https://www.cdc.gov/hiv/risk/ substanceuse.html

26. Chen X, Murphy DA, Naar-King S, Parsons JT. Adolescent Medicine Trials Network for HIVAI. A clinic-based motivational intervention improves condom use among subgroups of youth living with HIV. J Adolesc Health. 2011,49:193-198.

27. Velasquez MM, von Sternberg K, Johnson DH, Green C, Carbonari JP, Parsons JT. Reducing sexual risk behaviors and alcohol use among HIVpositive men who have sex with men: a randomized clinical trial. J Consult Clin Psychol. 2009,77:657-667.

28. Murphy DA, Brecht ML, Herbeck DM, Huang D. Trajectories of HIV risk behavior from age 15 to 25 in the national longitudinal survey of youth sample. J Youth Adolesc. 2009,38:1226-1239.

29. Dedoose version 5.0.11, Web application for managing, analyzing, and presenting qualitative and mixed method research data. Los Angeles, CA: Sociocultural Research Consultants LLC; 2014.

30. Reback CJ, Larkins S, Shoptaw S. Changes in the meaning of sexual risk behaviors among gay and bisexual male methamphetamine abusers before and after drug treatment. AIDS Behav. 2004,8:87-98.

31. Yi H, Sandfort TG, Shidlo A. Effects of disengagement coping with HIV risk on unprotected sex among HIV-negative gay men in New York City. Health Psychol. 2010,29:205-214.

32. Kelly BC, Bimbi DS, Izienicki H, Parsons JT. Stress and coping among HIV-positive barebackers. AIDS Behav. 2009,13:792-797.

33. Martin JI, Pryce JG, Leeper JD. Avoidance coping and HIV risk behavior among gay men. Health Soc Work. 2005,30:193-201.

34. Gowda C, Coppock D, Brickman C, Shaw PA, Gross R. Determinants of HIV Transmission Risk Among HIV-Infected Persons Engaged in Care. AIDS Educ Prev. 2016,28:440-452.

35. Alvy LM, McKirnan DJ, Mansergh G, Koblin B, Colfax GN, Flores SA, et al. Depression is associated with sexual risk among men who have sex with men, but is mediated by cognitive escape and self-efficacy. AIDS Behav. 2011,15:1171-1179.

36. Herbst JH, Sherba RT, Crepaz N, Deluca JB, Zohrabyan L, Stall RD, et al. A meta-analytic review of HIV behavioral interventions for reducing sexual risk behavior of men who have sex with men. J Acquir Immune Defic Syndr. 2005,39:228-241.

37. Broeckaert L, Challacombe L. Disclosure programming: a review of the evidence. Prevention in Focus. 2016.

38. Wolitski RJ, Gomez CA, Parsons JT. Effects of a peer-led behavioral intervention to reduce HIV transmission and promote serostatus disclosure among HIV-seropositive gay and bisexual men. AIDS. 2005, $19 \mathrm{Suppl}$ 1:S99-109.

39. Carballo-Dieguez A, Ventuneac A, Dowsett GW, Balan I, Bauermeister $\mathbf{J}$, Remien RH, et al. Sexual pleasure and intimacy among men who engage in "bareback sex". AIDS Behav. 2011,15 Suppl 1:S57-65.

40. Balan IC, Carballo-Dieguez A, Ventuneac A, Remien RH. Intentional condomless anal intercourse among Latino MSM who meet sexual partners on the Internet. AIDS Educ Prev. 2009,21:14-24.

41. Mallory C. African American women's experience of infection with HIV in the rural southeastern United States. J Assoc Nurses AIDS Care. 2008,19:28-36.

42. Chariyeva Z, Golin CE, Earp JA, Suchindran C. Does motivational interviewing counseling time influence HIV-positive persons' self-efficacy to practice safer sex?, Patient Educ Couns. 2012,87:101-107.

43. Carey MP, Braaten LS, Maisto SA, Gleason JR, Forsyth AD, Durant LE, et al. Using information, motivational enhancement, and skills training to reduce the risk of HIV infection for low-income urban women: a second randomized clinical trial. Health Psychol. 2000,19:3-11.

44. Kiene SM, Barta WD. A brief individualized computer-delivered sexual risk reduction intervention increases HIV/AIDS preventive behavior. J Adolesc Health. 2006,39:404-410. 